\section{$\underset{\text { hommes }}{\text { \& migrations }}$}

\section{Hommes \& migrations}

Revue française de référence sur les dynamiques

migratoires

$1303 \mid 2013$

Diasporas marocaines

\title{
Né quelque part
}

Film français de Mohamed Hamidi (2013)

\section{Simon Pellegry}

\section{OpenEdition \\ 1 Journals}

\section{Édition électronique}

URL : http://journals.openedition.org/hommesmigrations/2605

DOI : 10.4000/hommesmigrations.2605

ISSN : 2262-3353

\section{Éditeur}

Musée national de l'histoire de l'immigration

\section{Édition imprimée}

Date de publication : 1 juillet 2013

Pagination : 204-205

ISBN : 978-2-919040-23-0

ISSN : $1142-852 X$

\section{Référence électronique}

Simon Pellegry, « Né quelque part », Hommes \& migrations [En ligne], 1303 | 2013, mis en ligne le 22 janvier 2014, consulté le 22 septembre 2020. URL : http://journals.openedition.org/

hommesmigrations/2605; DOI : https://doi.org/10.4000/hommesmigrations.2605

Ce document a été généré automatiquement le 22 septembre 2020.

Tous droits réservés 


\section{Né quelque part}

Film français de Mohamed Hamidi (2013)

\section{Simon Pellegry}

1 Président et cofondateur du Bondy Blog, militant associatif, Mohamed Hamidi vient de réaliser son premier film, Né quelque part, présenté en séance spéciale au Festival de Cannes 2013. Sorte de récit autobiographique annoncé par les premiers mots du film, “ on n'est jamais trop curieux quand il s'agit de sa propre histoire", le film oscille entre comédie douce-amère et observation sociologique autour des questions identitaires d'un fils d'immigré obligé de revenir au pays.

2 C'est par un argument de scénario banal que le film commence. Suite à un malaise, un père demande à son fils, Farid, étudiant en droit, d'aller immédiatement sauver la maison familiale de la démolition dans son pays d'origine, l'Algérie. Mais alors que l'Algérie est la patrie mère pour le père, elle reste inconnue au fils. "Moi en Algérie? Mais je parle même pas l'arabe !", dit-il abasourdi.

Commencé au niveau des racines, le film progresse vers le ciel. Farid est littéralement aveuglé par le soleil brûlant méditerranéen, tandis qu'il découvre la maison familiale. Sans trop de surprises, le voici plongé dans ce monde inconnu dont il est pourtant originaire. Le film, oscillant entre l'ocre-bleu du ciel et le beige-marron de la terre, conte l'ouverture des yeux de Farid au rythme de ses découvertes.

3 Au départ, c'est un cousin qui joue le guide. Interprété par le facétieux Jamel Debbouze, ce miroir de Farid incarne le reflet de ce qu'aurait pu être sa vie si son père était resté en Algérie. Mais l'un est né ici et l'autre là-bas et leurs vies ont été d'autant plus différentes que Farid ignore tout de l'Algérie quand son cousin ne rêve que de la France. Cet aveuglement de la deuxième génération d'immigrés sur ses racines sera le moteur du reste du film entre quête identitaire et comédie situationniste accumulant les gags sur la langue, le français de Paris et le français du bled...

4 Au cours d'une soirée mouvementée, Farid ne voit pas son cousin lui dérober ses papiers d'identité. Si l'allégorie est un peu lourde, elle aura de véritables conséquences sur le récit. Afin de retrouver une chance de rentrer en France, le voici obligé de se réinventer sans cesse de nouvelles identités. Parce qu'au fond, Farid ne sait pas 
vraiment qui il est, d'où il vient, ni quels sacrifices l'ont amené à naître si loin de cette terre qu'il a choisi d'ignorer.

5 Le retour à Paris, tant attendu et souhaité, se complique, occasion pour le réalisateur d'aborder la réalité quotidienne des échanges Nord/Sud... et, en particulier, la question des visas refusés. Remarquant que chaque lettre commence par la même froideur administrative - "Nous avons le regret de vous..." -, Moustafa assène tristement: "La France n'a que des regrets à nous envoyer." Ce lien entre la France et l'Algérie évoqué au travers des relations entretenues par la diaspora est incarné dans le film par l'un de ses personnages les plus cocasses, Fatah, "le standardiste du café secteur".

Gardien du seul téléphone du village, Fatah est préposé à décrocher avec empressement l'appareil à la première sonnerie alors que tout le monde tend l'oreille aux conversations. Allégorie fantasque du téléphone arabe, Fatah est un personnage pittoresque parmi la galerie de caractères que le film entend dresser tout au long du périple de Farid.

$7 \quad$ Né quelque part manque malheureusement son coup, préférant parfois le raccourci à l'étude, le poncif à la nuance. Toutefois, il semble augurer un nouveau regard sur la diaspora algérienne qui ne veut rien savoir de ses origines. Au regard d'un cinéma commercial prompt à la caricature et au cliché, Né quelque part semble toutefois ouvrir une brèche dans laquelle, on l'espère, d'autres oseront s'aventurer. 